\title{
A park for the Barbary macaques of Gibraltar?
}

\author{
Julia E. Fa
}

The two Barbary macaque troops on the Rock of Gibraltar have long attracted countless numbers of tourists, yet no benefit to this endangered species has ever resulted. Rather, some visitors feed and disturb the monkeys of the Queen's Gate group, with drastic consequences for their activity, breeding and general condition. The author, who has worked with the species on the Rock and in the wild in North Africa, proposes the establishment of a park, which would protect the Queen's Gate troop, generate funds for conservation, and act as an education centre.

Since they were first introduced, probably more than 240 years ago, the Barbary maraques Macaca sylvanus of Gibraltar have experienced varying degrees of attention from the human inhabitants (Fa, 1981). The British Army has successfully maintained a stock of about 40 animals, in two troops, at Queen's Gate and Middle Hill, for the past 73 years, but the present management system does not exploit the full educational and commercial potential of such an important population of animals. The present staff, a keeper and an assistant, requisition the food, feed and control the animals and occasionally act as guides. However, they do this in addition to their normal duties as soldiers, and as a consequence, the Queen's Gate troop is not supervised all the time. Tourists tease the monkeys, feed them undesirable foods and even maltreat them. Despite notices prohibiting feeding, in 1979 a significant number of people gave the monkeys food ranging from sweets to melons (Fa, in press). The effect of such overfeeding is reflected in a high incidence of obesity and high levels of aggression associated with the manner of feeding ( $\mathrm{Fa}, 1984)$. Such contact with humans also seems to affect breeding; there is a significant negative correlation between the numbers of visitors to Gibraltar and annual birth rates in the two troops of monkeys, especially in the Queen's Gate troop (Fa, 1984).

242
The Apes' Den in Gibraltar, where the Queen's Gate troop is found, draws large numbers of visitors. In 1979, when the frontier with Spain was still closed, more than 40,000 people, 40 per cent of the total number of tourists, visited the monkeys ( $\mathrm{Fa}$, in press). In the year following the full opening of the frontier in February 1985, the total number of tourists visiting the Rock (and proportionately the monkeys) exceeded two million, according to the Gibraltar Tourist Office (Figure 1). Despite this remarkable number of visitors in a city whose economy is largely dependent on tourism, little commercial use has been made of this tourist attraction.

In contrast, three parks of Barbary macaques owned by Baron Gilbert de Turckheim have proved to be an outstanding commercial success (de Turckheim and Merz, 1984). Since 1976 more than three million people have visited these parks (two in France at Kintzheim, Alsace, and Rocamadour, Lot, and one in Germany at Salem), making them very profitable. A reasonable entrance fee, the sale of quality souvenirs and the availability of refreshments on the site (outside the monkey enclosures) have all contributed to the parks' success. Exhibition areas displaying aspects of the monkeys' behaviour, life history and conservation provide stimulating background information both for the ordinary

Oryx Vol 21 No 4, October 1987 
visitor and for school parties. The animals benefit both from the closer supervision of visitors by wardens, who prevent harassment and excessive feeding, and from the scientific scrutiny of the monkey groups, which ensures that they receive adequate veterinary care and a balanced diet.

\section{The case for a monkey park on Gibraltar}

The re-opening of the Gibraltar border with Spain has aggravated the problem of uncontrolled exposure of the monkeys to the public. It would be wise to rectify the situation by establishing a park along the lines of the Turckheim ones. Apart from its commercial and conservational attributes, such a park on Gibraltar would provide an ideal base for scientific research into the behaviour and ecology of the species. The information gained would contribute greatly to the understanding and protection of the animal in its natural habitat across the Straits. Some universities

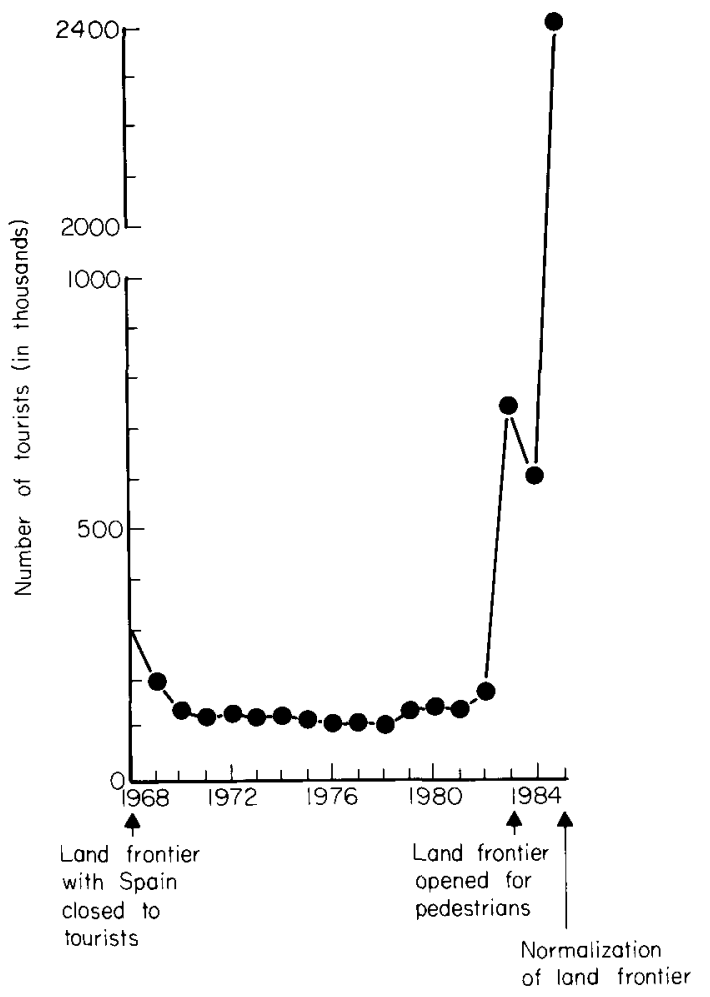

Figure 1. The increase in visitor numbers to Gibraltar in recent years.

Barbary macaques of Gibraltar
(Toronto in Canada, and St Andrews and Oxford in the UK) have shown an interest already by carrying out various projects on both monkey troops on the Rock. This kind of interest could be further encouraged by having a scientific establishment based on the Rock, which would be able to create strong links between scientific bodies throughout the world. Such a scientific establishment would also be of immense educational value for schools and colleges in Gibraltar itself.

As well as the prime project of conserving the monkey population, the establishment of the park would have other advantages: it would contribute to the conservation of other plant and animal species in Gibraltar since a protected area would be set aside, and Gibraltar's economy would benefit from providing services to the park.

\section{Establishment of the park}

\section{The proposed site}

The plan of the proposed park is shown in Figure 2. It has a surface area of approximately 9 ha $(22$ acres) and is largely covered by dense low scrub of wild olive Olea europaea, lentisc Pistacia lentiscus and a buckthorn Rhamnus alaternus, with scattered tall Aleppo pines Pinus halepensis. The site includes a cliff system about $400 \mathrm{~m}$ long and $30 \mathrm{~m}$ high, and gradients range from cliff (1:1) to $1: 3$. Three abandoned gun emplacement batteries from World War II would be incorporated into the park. Access to the site is proposed at three locations indicated in Figure 2: (1) at the Apes'Den; (2) at the junction of Queen's Road and the Rooke Battery access road (Service entrance); and (3) a pedestrian access on the western boundary from the Europa Road/Green Lane area.

\section{Provision of facilities}

An upper 'viewing path' linking entrances 1 and 2 , and commanding views of the lower parts of the site where the monkeys would roam, as well as of the town and harbour would give the public maximum access. The viewing path would incorporate excellent vantage points and, at the lower levels of the site, nature trails would be cleared.

At the main entrance a shop would sell items of 
general interest, and also popcorn which visitors would be allowed to feed to the monkeys as it is of low calorific value. Maps would be provided and visitors would be drawn on to the 'viewing path' leading to Rooke Battery, where there would be refreshment facilities. It is essential that visitors eating and drinking should be strictly, but unobtrusively, restricted to this area so as to avoid unauthorized feeding of the monkeys.

The main focus of the park, Rooke Battery, would contain: (1) an exhibition of Gibraltarian and Mediterranean wildlife with a permanent display concentrating on the Barbary macaque; (2) research facilities for the continuous monitoring of the monkey population and for the use of visiting researchers; (3) park management offices; and (4) a workshop, holding cages and storage facilities for park maintenance.

\section{Management}

In general, those parts of the programme that deal with public access, wardening and interpretation would be undertaken by permanent ground staff, while those relating to the survey, monitoring and manipulation of the animals as well as scientific research would be co-ordinated by a park director.

Most of the land would have to be cleared to achieve a predominance of steppe or garrigue

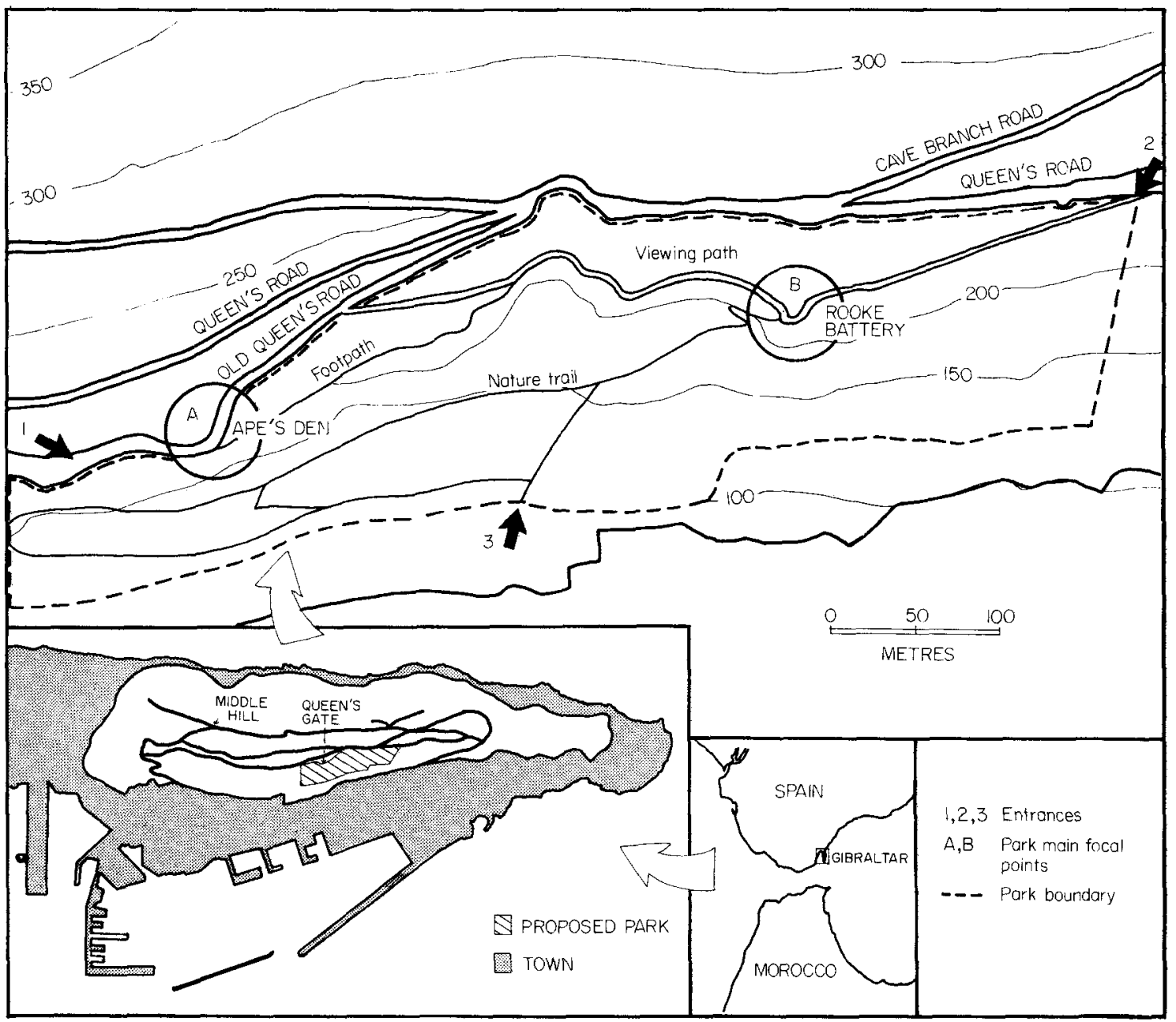

Figure 2. The location of the proposed monkey park in Gibraltar. 
vegetation (grass and herbaceous vegetation) on which monkeys feed (Fa, 1986). Emerging woody vegetation would be cleared occasionally in order to maintain this habitat, but the taller trees should be left. Wherever possible the natural history interest within the park and its surroundings would be conserved.

\section{Monitoring and research}

The design of the park should enable close observation of the animals and facilitate daily checks on any pathological cases. All animals would be trapped annually to check their physical condition, take blood samples and X-rays, weigh and measure them, and vaccinate them against rabies. It would take at least one month to trap and process all individuals, and a veterinary surgeon would supervise such work.

Research dealing with aspects of maternal behaviour, alloparental behaviour, socialization of infants, group social dynamics and reproductive behaviour as well as the ecology of the species would be encouraged. This would provide the necessary scientific bases to further the proper management of the colony.

\section{Management and research policy decision making}

The park director would be responsible for any decision concerning the management of the monkeys. However, it is recommended that a committee, which should include primatologists and conservationists, be set up in order to advise on animal management and on research topics to be tackled. Workers in universities would be encouraged to submit projects for research both in the park and in North Africa, which would be fostered and supervised by the park establishment in Gibraltar. Some of the park profits could be allocated for research.

\section{Funding}

The method of funding for the setting up of the park would depend on whether the Gibraltar Government decides to open it up to a private concern or to finance it via government resources. The initial costs for establishing the park are considered to be low since most of the Barbary macaques of Gibraltar building foundations and paths already exist. Given the volume of tourists, the goal of making the park self-financing is not unrealistic. By way of an example, an initial investment of $£ 1$ million could be repaid in only four years (if it were an interest-free loan from development agencies, for example) with only 250,000 visitors to the park each paying a $£ 1$ entrance fee, after deducting the running costs.

\section{Conclusions}

The establishment of a monkey park in Gibraltar is appropriate in Gibraltar's present economic situation. The long-established appeal of the macaques on Gibraltar is currently unmatched by any other element of the Rock's biology and should be used to the full to benefit not only the macaques and the economy, but also Gibraltar's wildlife in general.

\section{Acknowledgments}

I am especially grateful for the support the project has received from the Primate Society of Great Britain through its Working Party for Conservation. I thank Dr Bill McGrew, Dr David Chivers, Dr Miranda Stevenson, Dr Robin Dunbar, Mr Ian Pankhurst and Baron Gilbert de Turckheim. I would also like to extend my thanks to Mr Cyril Rosen, UK representative of the International Primate Protection League, for his constant enthusiasm and firm support in this venture. To my wife Monique I give my warmest thanks for her ever present help and encouragement.

\section{References}

Fa, J.E. 1981. The apes on the Rock. Oryx, 16, 73-76.

$\mathrm{Fa}$, J.E. 1984. Structure and dynamics of the Barbary macaque population in Gibraltar. In The Barbary Macaque - A Case Study in Conservation (Ed. J. E. Fa), pp. 263-306. Plenum Press, New York.

Fa, J.E. 1986. Use of Time and Resources by Provisioned Troops of Monkeys: Social Behaviour, Time and Energy in the Barbary Macaque (Macaca sylvanus L.) at Gibraltar. Contributions to Primatology No. 23, Basle, Switzerland.

Fa, J.E. In press. Provisioned food as a supernormal stimulus - a case study from the Barbary macaques (Macaca sylvanus L.) in Gibraltar. In Ecology and Behavior of Food-Enhanced Primate Groups (Eds J. E. Fa and C. H. Southwick). Alan Liss, New York.

de Turckheim, G. and Merz, E. 1984. Breeding Barbary macaques in outdoor open enclosures. In The Barbary Macaque-A Case Study in Conservation (Ed. J. E. Fa), pp. 241-261. Plenum Press, New York.

John E. Fa, Departamento de Ecologia, Instituto de Biologia, Universidad Nacional de Mexico, Apartado Postal 70-233, Mexico 04510. 